Seda SUCU

Adem YAĞCl

Gaziosmanpaşa Üniversitesi, Ziraat Fakültesi, Bahçe Bitkileri Bölümü, 60250, Taşlıçiftlik / TOKAT

sorumlu yazar: seda.sucu@gop.edu.tr

Anahtar Sözcükler:

Filoksera, amerikan asma anacı, fidan randımanı

Key Words:

Phylloxera, sapling yield, rootstock

\section{Bazı Asma Anaçları ve Bu Anaçlar Üzerine Aşılı Sultani Çekirdeksiz Çeşidinde Fidan Randımanı ve Kalite Özelliklerinin Belirlenmesi}

\author{
Determination of Sapling Yield and Quality Features in Some \\ Rootstocks and Sultanı Çekırdeksız (Vitis Vinifera L.)Variety \\ Grafted on These Rootstoks
}

Alını̧ (Received): 25.07.2016 Kabul tarihi (Accepted): 11.10.2016

\section{ÖZET}

-iloksera zararlısının varlığı asma yetiştiriciliğinin yapıldığı topraklarda, anaç - kullanımını zorunlu hale getirmiştir. Ancak bu anaçları seçerken dikkat edilmesi gereken bazı hususlar vardır. Bunlardan biriside anaç ve çeşit arasındaki uyum ve bu uyumun fidan randımanı ve kalitesi üzerine olan etkisidir. Çalışmada; ülkemizde kullanılan Amerikan asma anaçlarının bir çoğunun (Rup. du Lot, 420A, 5BB, SO4, 8B, 110R, 1103P, 140 Ru, 41 B, Ramsey) kendi kökleri üzerine aşıSız olarak ve Sultani Çekirdeksiz çeşidi ile aşılanmaları ile aşılı olarak yetiştirilen bitkiler kullanılmıştır. Aşılı ve aşısız bitkilerde randıman ve kalite özellikleri incelenmiştir. Fidan randımanı ve kalite kriterleri açısından aşıı ve aşısız bitkiler kendi aralarında değerlendirildiklerinde incelenen parametreler bakımından farklar istatistiki açıdan önemli bulunmuştur. Aşılı bitkiler arasında fidan randımanı bakımından; S.Ç/ Rupestris du Lot (\%54), S.Ç/5BB (\%54) kombinasyonu ön plana çıkarken aşısız bitkilerde Sultani Çekirdeksiz çeşidi (\%84) ve 5BB (\%82) anacı ön plana çıkmıştır. Kök uzunluğu bakımından aşılı bitkilerde S.Ç/1103P (110 $\mathrm{mm})$ ve S.Ç/110R (102 $\mathrm{mm})$ kombinasyonu, aşısız bitkilerde 1103P, 8B (73 mm) anaçları ön plana çıkmıştır. Yaş ve kuru kök ağırlığı bakımından aşılı bitkilerde S.Ç/1103P (2.8-1.8 g) , S.Ç/110R (3-1.9 g), aşısız bitkilerde $140 \mathrm{Ru}$ (2.8-1.6 g), 5BB (1.8-1.6 g) anaçları ön plana çıkmıştır.

\section{ABSTRACT}

T he use of rootstocks in vine cultivation areas has become inevitable due to the excessive damages caused by phylloxera. However, there are some necessary measures which need to be considered during the selection procedure of these rootstocks. The harmony between rootstock and varieties, and effects of this harmony on sapling yield and quality are among one of these measures. Many American grapevine rootstocks being used in Turkey (Rup. du Lot, 420A, 5BB, SO4, 8B, 110R, 1103P, 140 Ru, 41 B, Ramsey) grown as non-grafted on their own roots and grafted with Sultani seedless variety were used in the current study. Sapling yield and quality traits of grafted and non-grafted rootstocks were investigated during the study. The tested grafted and non-grafted rootstocks significantly $(p \leq 0.05)$ differed from each other for investigated yield and quality parameters. The S.Ç/Rupestris du Lot and S.Ç/5BB combinations of grafted rootstocks were the most successful with $54 \%$ sapling yield whereas Sultani seedless variety were found to be most successful ( 84 and $82 \%$ sapling yield respectively) among non-grafted rootstocks. Similarly S.C /1103P and S.Ç/110R combinations of grafted root stocks with 110 and $102 \mathrm{~mm}$ root length respectively were most prominent with respect to root length. Whereas, 1103P and $8 \mathrm{~B}(73 \mathrm{~mm}$ root length) were the most successful non-grafted rootstocks in this regard. S.C/1103P (2.8-1.8 g) and S.C/110R (3-1.9 g) combinations of grafted rootstocks and $140 \mathrm{Ru}(2.8-1.6 \mathrm{~g}), 5 B B(1.8-1.6 \mathrm{~g})$ non-grafted rootstocks were the most evident ones with respect to fresh and dry weight. 


\section{GíRiş}

Bağcilıkta çoğaltma tohum veya çelikle yapılabilmektedir. Ancak birçok meyve türlerinde olduğu gibi bağcllıkta da çoğaltma vejetatif olarak yapılmaktadır. 1881'li yıllarda Anadolu topraklarını etkisi altına alan filoksera zararlısı nedeniyle asma fidanı üretiminde Amerikan asma anaçları kullanılmaktadır (Biron, 1948; Morton, 1979). Filoksera zararlısı Vitis vinifera L. türünün köklerine zarar verirken, Amerikan asma anaçlarının köklerine zarar verememektedir. Bu durum asma fidan üretiminde Amerikan asma anacı kullanmayı kaçınılmaz kılmaktadır (Carew ve ark., 2004; Çelik, 2011). Asma fidanı üretimi; Amerikan asma anaçları ile yetiştiricilik yapılmak istenen çeşidin masabaşında veya arazi şartlarında (yerinde) aşılanması ile gerçekleştirilmekte ve bağlar bu fidanlar ile tesis edilmektedir (Çelik ve ark., 1998).

Filoksera zararlısı Amerikan asma anacı kullanımı zorunlu hale getirmiştir. Ancak aşılamada kullanacağımı anacı belirlerken göz önünde bulundurulması gereken bazı hususlar vardır. Bunlar; adaptasyon (toprak-anaç ilişkisi), afinite (anaç-kalem ilişkisi), filokseraya dayanım (anaç-filoksera ilişkisi), nematoda dayanım (anaç-nematod ilişkisi), diğer unsurlar (dalların odunlaşma düzeyi, çeliklerin köklenme yeteneği, anacın gelişme kuvveti v.b) (Çelik ve ark., 1998; Çelik, 2011). Asma yetiştirme tekniklerinde ise; taç yönetimi (Hunter ve Le Roux, 1992), birim alandaki bitki sayısı (Archer ve Strauss, 1985; 1989; Hunter, 1998), kullanılan anaç-çeşit kombinasyonu (Harmon ve Snyder, 1934; Tandonnet ve ark., 2010) oldukça önemlidir.

Anaç- kalem kombinasyonu arasındaki ilişki asmada vejetatif gelişmeyi ve verimi etkilemektedir (Santrosa ve ark., 2016). Farklı anaç ve çeşitlere ait kombinasyonlarla yapılan aşılama sonucu elde edilen fidan randıman ve kalitesi; kombinasyonlara göre değişebileceği birçok araştırıcı tarafından bildirilmiştir (Yağcı ve Aydin, 2015; Aslan ve ark., 2015; Iş̧çi ve ark., 2015; Persuric ve ark., 2015; Yağcı ve Gökkaynak, 2016). Cangi ve arkadaşları (1999), 46 adet aşı kombinasyonunda fidan randımanının \% 8.9-73.3 arasında kombinasyonlara bağlı olarak değiştiğini tespit etmişlerdir. Yine aynı şekilde farklı anaç- çeşit kombinasyonları ile anaç ve çeşit arasında; kallus gelişim düzeyi, sürgünlerin odunlaşma düzeyi, sürgün uzunluğu, yaş-kuru sürgün ağırlıkları bakımından görülen farkıııklar yapılan çalışmalar ile bildirilmiştir (Illhan ve ark., 1991; Atlı ve Arpacı, 1993; Sivritepe ve Türkben, 2001; Baydar ve Ece, 2005).

$\mathrm{Bu}$ çalışma ile ülkemizde kullanılan 10 adet Amerikan asma anacI (Rup. du Lot, 420A, 5BB, SO4, 8B,
110R, 1103P, $140 \mathrm{Ru}, 41 \mathrm{~B}$, Ramsey) hem kendi kökleri üzerinde hem de Sultani Çekirdeksiz çeşidi ile aşılanması ile elde edilen aşılı ve aşısız bitkilerde fidan randıman ve kalite özellikleri incelenmiştir.

\section{MATERYAL ve YÖNTEM}

\section{Materyal}

Çalışma 2014 yılında yürütülmüş olup, çalışmada kullanılacak bitkisel materyallerler; Sultani Çekirdeksiz'e ait K-7 klonu ve Rup. du Lot, 420A, 5BB, SO4, 8B, 110R, 1103 P, 140 Ru, 41 B, Ramsey anaçlarıdır. Bitkisel materyallerin tümü Manisa Bağcılık Araştırma Enstitüsü'nden temin edilmiştir.

\section{Yöntem}

Bitkisel materyaller aşılama dönemine kadar sıcaklık ve nemi kontrollü soğuk hava deposunda bekletilmiştir (Gerhardt ve ark., 1971; Ağaoğlu ve ark., 1978). Aşılama döneminde soğuk hava deposundan çıkarılan; Sultani Çekirdeksiz K-7 klonuna ait kalemler 1 gün, aşılama da kullanılacak anaçlara ait çelikler ise 2 gün süre ile suda bekletilmiştir. Aşılama öncesi bütün bitkisel materyaller $50^{\circ} \mathrm{C}$ de 30 dakika süre ile sıcak su uygulaması yapılmıştır (Archbold ve ark., 1997). Daha sonra sırasıyla; aşılama (masabaşı omega aşı), parafinleme (Actygref, France) ve çam talaşı ile katlama işlemlerini takiben aşılı fidanlar kaynaştırma odasına alınmıştır. Kaynaşsırma odası koşulları: 3 gün $28-29{ }^{\circ} \mathrm{C}$, 15 gün $25-26{ }^{\circ} \mathrm{C}$ ve 3 gün $22-24{ }^{\circ} \mathrm{C}$; nem oranı \%85-95; 6-12 saatte bir havalandırma (Çelik, 1983; Akman ve Ilgın, 1987) olacak şekilde düzenlenmiştir. Kaynaştırma odasından çıkarılan aşıı fidanlar, 2 gün süre ile dışarıda bekletilip, talaş temizleme işleminin ardından ikinci parafinleme yapılmıştır. Bu işlemin ardından serada içerisinde harç materyali olarak torf, perlit karışımı (torf ve perlit, 1:1 $\mathrm{v} / \mathrm{v}$ ) bulunan $8 \mathrm{~cm} \times 16 \mathrm{~cm}$ ebadındaki tüpler içerisine dikimi (26.04.2014) gerçekleştirilmiştir. Dikim öncesi aşılı materyalin diplerine 2000 ppm'lik IBA (Indol Bütirik Asit) ile hızlı daldırma yapılmıştır (Sağlam ve ark., 2005).

Aşısız olarak yetiştirilecek çelikler ise soğuk hava deposundan çıkarılıp 4 gün oda koşullarında, daha sonra ise 2 gün süre ile suda bekletilmelerinin ardından termoterapi $\left(50^{\circ} \mathrm{C}\right.$ de 30 dak.) uygulamaları yapılmıştır. Aşısız olarak kullanılacak olan bitkilerin alt ve üst göz hariç diğer gözlerinde köreltme yapılmış ve ardından sera içerisindeki tüplere dikilmişlerdir. K-7 klonuna ait kalemlerde 1 gün süre ile suda bekletilip, üzerlerinde yaklaşık 4-5 göz taşıyan çelikler haline getirilip tüplere dikimi (26.04.2014) gerçekleştirilmiştir. 
Serada gelişimlerini tamamlayan aşılı ve aşısız fidanlara (10.06.2014), düzenli olarak bakım işleri (sulama, anaçtan süren sürgünlerin temizlenmesi v.b) gerçekleştirilmiştir.

- Fidan randımanı (\%): Vejetasyon periyodu sonunda elde edilen sağlıkı kök ve sürgün sistemine sahip fidan sayısının, başlangıçta dikilen aşılı ve/veya aşısız çelik sayısına bölünerek 100 'le çarpılması suretiyle hesaplanılmıştır.

- Kök uzunluğu $(\mathrm{cm})$ : Çeliklerde oluşan köklerin uzunlukları dip kısımdan itibaren cetvel ile ölçülerek yapılmıştır.

- Yaş-kuru kök ağırlığı (g): Çeliklerin kökleri budama makası ile temizlenerek öncelikle yaş ağırlığı, neminin tamamen uzaklaştırımasından sonrada kuru ağırlığı tartılarak hesaplanmıştır.

- Deneme Deseni ve İstatistiki Analizler: Aşılı ve aşısız fidanlarda değerlendirmeler ayrı ayrı yapılmıştır. Her bir anaç için aşılı fidanlarda 10 anaç $x 1$ çeşit $x 3$ tekerrür $x$ 30 çelik; aşısız fidanlarda ise 10 anaç $\times 3$ tekerrür $\times 30$ çelik kullanılmıştır. Deneme tesadüf parselleri deneme desenine göre yapılmış olup elde edilen veriler varyans analizine tabii tutulmuş ve ortalamaların karşılaştırılmasında $\mathrm{LSD}_{0,05}$ testinden faydalanılmıştır.

\section{ARAŞTIRMA BULGULARI ve TARTIŞMA}

Sultani Çekirdeksiz üzüm çeşidinin K-7 klonuna ait kalemlerin farklı anaçlara aşılanması sonucu elde edilen aşılı bitkilerde toplam fidan randımanı, kök uzunluğu, yaş ve kuru kök ağırlığı istatistiki açıdan önemli bulunmuştur (Çizelge 1). Çizelge 1'de görüldüğü gibi farklı anaç üzerine aşıı Sultani Çekirdeksiz (K-7 klonu) çeşidinde toplam fidan randımanı en yüksek olan kombinasyonlar \%54 ile S.Ç/Rupestris du Lot ve S.Ç/5BB anaçları olurken bunu $\% 52$ fidan randıman oranı ile S.Ç/1103P, S.Ç/SO4, S.Ç/8B, \%48 ile S.Ç/420A, S.Ç/Ramsey, \%38 ile S.Ç/110R, \%32 ile S.Ç/41 B ve kombinasyonları izlemiştir. En düşük fidan randımanı oranı ise \%20 ile S.Ç/140 Ru kombinasyonu göstermiştir.

Kök uzunluğu değerleri açısından bakıldığında; S.Ç/1103P kombinasyonu $110 \mathrm{~mm}$ ile en uzun kök değerine sahip olmuştur. Sıralama S.Ç/110R (102 mm), S.Ç/Rupestris du Lot $(91 \mathrm{~mm})$, S.Ç/Ramsey $(81 \mathrm{~mm})$, S.Ç/41 B (77 mm), S.Ç/8B $(69 \mathrm{~mm})$, S.Ç/420A $(68 \mathrm{~mm})$, S.Ç/140 Ru ve S.Ç/SO4 (65 mm), S.Ç/5BB $(62 \mathrm{~mm})$ şeklinde değişmektedir (Çizelge 1).

Çizelge 1. Aşılı bitkilere ait toplam fidan randıman oranı (\%), kök uzunluğu (mm), yaş ve kuru kök ağırlığı (gr)

Table 1. Total sampling yield (\%), root length $(\mathrm{mm})$, wet and dry root weight (gr) related to grafted plants

\begin{tabular}{lcccc}
\multicolumn{1}{c}{ Aşılı bitkiler } & $\begin{array}{c}\text { Fidan } \\
\text { Randımanı (\%) }\end{array}$ & $\begin{array}{c}\text { Kök } \\
\text { Uzunluğu }(\mathrm{mm})\end{array}$ & $\begin{array}{c}\text { Yaş kök } \\
\text { Ağırlığı (g) }\end{array}$ & Kuru kök ağırlı̆̆ (g) \\
\hline S.Ç/Rup. Du Lot & $54 \mathrm{a}$ & $91 \mathrm{bc}$ & $2.4 \mathrm{bc}$ & $1.5 \mathrm{abc}$ \\
S.Ç/420A & $48 \mathrm{ab}$ & $68 \mathrm{def}$ & $1.5 \mathrm{ef}$ & $1.1 \mathrm{bcd}$ \\
S.Ç/5BB & $54 \mathrm{a}$ & $62 \mathrm{f}$ & $1,7 \mathrm{de}$ & $1.0 \mathrm{~cd}$ \\
S.Ç/SO4 & $52 \mathrm{ab}$ & $65 \mathrm{ef}$ & $2.1 \mathrm{~cd}$ & $1.6 \mathrm{ab}$ \\
S.Ç/8B & $52 \mathrm{ab}$ & $69 \mathrm{def}$ & $1.3 \mathrm{f}$ & $0.9 \mathrm{~cd}$ \\
S.Ç/110R & $38 \mathrm{bc}$ & $102 \mathrm{ab}$ & $3.0 \mathrm{a}$ & $1.9 \mathrm{a}$ \\
S.Ç/1103P & $52 \mathrm{ab}$ & $110 \mathrm{a}$ & $2.8 \mathrm{ab}$ & $1.8 \mathrm{a}$ \\
S.Ç/140 Ru & $20 \mathrm{~d}$ & $65 \mathrm{ef}$ & $2.3 \mathrm{c}$ & $1.5 \mathrm{abc}$ \\
S.Ç/41 B & $32 \mathrm{~cd}$ & $77 \mathrm{de}$ & $1.7 \mathrm{de}$ & $1.2 \mathrm{bcd}$ \\
S.Ç/Ramsey & $48 \mathrm{ab}$ & $81 \mathrm{~cd}$ & $2.5 \mathrm{bc}$ & $1.5 \mathrm{abc}$ \\
LSD 0,05 & 15.1 & 13.3 & 0.43 & 0.51 \\
\hline
\end{tabular}

Aynı sütundaki farklı harfler önemlidir $(0,05)$

En fazla yaş ve kuru kök ağırlığı $3.0 \mathrm{~g}-1.9 \mathrm{~g}$ ile S.Ç/110R kombinasyonunda meydana gelmiştir. Bunu 2.8 g-1.8 g ile S.Ç/1103P kombinasyonu takip etmiştir. En az yaş ve kuru kök ağırlığı değeri ise $1.3 \mathrm{~g}-0.9 \mathrm{~g}$ ile S.Ç/8B kombinasyonundan elde edilmiştir (Çizelge 1.).

Asma anaçlarına ait aşıık çeliklerin aşısız olarak köklendirilmesi sonucu elde edilen aşısız bitkilerde; fidan randımanı, kök uzunluğu, yaş ve kuru kök ağırlığı değerleri Çizelge 2.'de verilmiştir.

Çizelge 2' de görüldüğü gibi toplam fidan randımanı bakımından en yüksek oran Sultani Çekirdeksiz (\%84) çeşidinde görülürken sıralama 5BB (\%82), 1103P (\%80), 8B (\%74), Rupestris du Lot ( \%72), SO4 (\%72), Ramsey (\%72), 41 B (\% 66), 420A (\% 66), 110R (\% 66), 140 Ruggeri (\% 60) şeklinde değişmiştir.

Kök uzunluğu bakımından en yüksek değer $73 \mathrm{~mm}$ ile $8 B$ ve $1103 \mathrm{P}$ anaçlarına ait aşısız bitkilerde görülürken onları sırasıyla; Rupestris du Lot $(71 \mathrm{~mm})$, Sultani Çekirdeksiz (70 mm), $140 \mathrm{Ru}(70 \mathrm{~mm}), 41$ B (67 $\mathrm{mm}), 420 \mathrm{~A}(64 \mathrm{~mm})$, Ramsey $(63 \mathrm{~mm}), \mathrm{SO} 4(59 \mathrm{~mm})$, 110R (56 mm), 5BB $(52 \mathrm{~mm})$ anaçlarına ait aşısız bitkiler takip etmiştir (Çizelge 2.). 
Çizelge 2. Aşısız bitkilere ait toplam fidan randıman oranı (\%), kök uzunluğu (mm), yaş ve kuru kök ağırlığı (gr) Table 2. Total sampling yield (\%), root length $(\mathrm{mm})$, wet and dry root weight (gr) related to non-grafted plants

\begin{tabular}{lcccc}
\multicolumn{1}{c}{ Aşısız bitkiler } & $\begin{array}{c}\text { Fidan randımanı } \\
(\%)\end{array}$ & $\begin{array}{c}\text { Kök } \\
\text { uzunluğu (mm) }\end{array}$ & $\begin{array}{c}\text { Yaş kök } \\
\text { Ağırlığı (g) }\end{array}$ & Kuru kök ağırlığı (g) \\
\hline Rup. Du. Lot & $72 \mathrm{abc}$ & $71 \mathrm{ab}$ & $0.9 \mathrm{~d}$ & $0.7 \mathrm{c}$ \\
$420 \mathrm{~A}$ & $66 \mathrm{bc}$ & $64 \mathrm{abcd}$ & $1.1 \mathrm{~cd}$ & $1.0 \mathrm{bc}$ \\
$5 \mathrm{BB}$ & $82 \mathrm{a}$ & $52 \mathrm{e}$ & $1.8 \mathrm{~b}$ & $1.5 \mathrm{a}$ \\
SO4 & $72 \mathrm{abc}$ & $59 \mathrm{cde}$ & $1.5 \mathrm{bc}$ & $1.3 \mathrm{ab}$ \\
$8 \mathrm{~B}$ & $74 \mathrm{ab}$ & $73 \mathrm{a}$ & $1.2 \mathrm{~cd}$ & $1.0 \mathrm{bc}$ \\
110 R & $66 \mathrm{bc}$ & $56 \mathrm{de}$ & $0.8 \mathrm{~d}$ & $0.7 \mathrm{c}$ \\
1103 Paulsen & $80 \mathrm{a}$ & $73 \mathrm{a}$ & $0.9 \mathrm{~d}$ & $0.7 \mathrm{c}$ \\
140 Ruggeri & $60 \mathrm{c}$ & $70 \mathrm{ab}$ & $2.8 \mathrm{a}$ & $1.6 \mathrm{a}$ \\
41 B & $66 \mathrm{bc}$ & $67 \mathrm{abc}$ & $1.5 \mathrm{bc}$ & $1.3 \mathrm{ab}$ \\
Ramsey & $72 \mathrm{abc}$ & $63 \mathrm{bcd}$ & $1.1 \mathrm{~cd}$ & $1.0 \mathrm{bc}$ \\
Sultani Çekirdeksiz & $84 \mathrm{a}$ & $70 \mathrm{ab}$ & $1.8 \mathrm{~b}$ & $1.2 \mathrm{ab}$ \\
LSD 0,05 & 12.6 & 0.95 & 0.47 & 0.41 \\
\hline
\end{tabular}

Aynı sütundaki farklı harfler önemlidir $(0,05)$

Aşısız bitkilere ait yaş ve kuru kök ağırlıkları incelendiğ inde $140 \mathrm{Ru}$ anacına ait aşısız bitkiler 2.8-1.6 g ile ilk sırada yer alırken sıralama 5BB (1.8-1.5 g), Sultani Çekirdeksiz (1.8; $1.2 \mathrm{~g}), 41 \mathrm{~B}$ ve SO4 $(1.5 ; 1.3 \mathrm{~g}), 8$ B (1.2; $1.0 \mathrm{~g}), 420$ A ve Ramsey $(1.1 ; 1.0 \mathrm{~g})$, Rupestris du Lot ve $1103 \mathrm{P} \quad(0.9 ; 0.7 \mathrm{~g}), \quad 110 \mathrm{R} \quad(0.8 ; \quad 0.7 \mathrm{~g})$ şeklinde değişmektedir (Çizelge 1.2.)

Asma fidanı üretiminde toplam fidan randımanı; anaca (Akman ve ark., 1989), çeşide (Cangi ve ark., 1999), çeşit/anaç kombinasyonuna göre (Çelik ve Ağaoğlu., 1979, 1981; Ergenoğlu ve Tangolar, 1990; Harmon ve Snyder, 1934; Tandonnet ve ark., 2010) farklılık göstermektedir. Samancı ve Uslu (1992), 8 adet Amerikan asma anacı ve 12 adet üzüm çeşidi ile yapmış oldukları çalışmada Rup. Du Lot anacının 140 Ru ve 41 B anacına göre daha iyi sonuç verdiğini bildirmektedir. Aynı şekilde Cangi ve arkadaşları (1999), 46 adet aşı kombinasyonunda fidan randımanının \% 8.9-73.3 arasında kombinasyonlara bağlı olarak değiştiğini tespit etmişlerdir.

Baydar ve Ece (2005), Isparta koşullarında üç anaç üzerine (SO4, 5 BB ve 1103 Paulsen) üç çeşidi (Razakı, Alphonse L. ve Italia) aşılamışlar ve toplam fidan randıman değerinin anaç/çeşit kombinasyonuna göre değişebileceğini bildirmişlerdir. Tunçel ve Dardeniz (2013), aşılı asma fidanı üretiminde çeşitli nedenler ile kayıplar yaşanabileceğini ve bunun neticesinde fidan randımanının \%25-57 arasında değişebildiği belirtilmektedir.

Dardeniz ve Şahin (2005) , 41 B, 5 BB, 1103 Paulsen ve 140 Ruggeri anaçları ile Uslu ve Yalova İncisi çeşitleri ile oluşturdukları kombinasyonlarda toplam fidan randımanına bakmışlardır. Uslu çeşidi için 41 B (\%44.61) anacı 5 BB (\%37.47) ve $140 \mathrm{Ru}(\% 28.75)^{\prime}$ ya göre en iyi sonucu verirken, Yalova incisi çeşidi için en iyi sonucu
$41 \mathrm{~B}(\% 38.79), 1103 \mathrm{~Pa}(\% 27.94)$ ve $140 \mathrm{Ru}(\% 27.13)$ anaçları vermiştir.

İşçi ve Altındişli (2006), yapmış oldukları çalışmada $41 \mathrm{~B}$ ve $110 \mathrm{R}$ anaçları üzerine Trakya Illkeren, Red Globe ve Yuvarlak Çekirdeksiz çeşitlerini aşılamışlar ve aşı tutma oranlarını incelemişlerdir. Sonuçlar incelendiğinde $41 \mathrm{~B}$ anacı $110 \mathrm{R}$ anacından daha yüksek bir performans göstermiştir.

Araştııııların ilk olarak bitkinin toprak üstü aksamına yönelmelerinden dolayı kökler ile ilgili yapılan çalışmalar daha sınırlıdır (Epstein, 2004). Sürgünün aksine toprak altındaki köke ulaşmak ve seçmek kolay olmadığı için kök çalışmaları çok daha zordur (Richards 1983; Johnson ve Gregory, 2006). Sucu ve Yağcı (2015)'nın yapmış oldukları çalışmada aşılama öncesi ön bekletme uygulamalarının fidan kalite ve randımanı üzerine olan etkisine bakılmıştır. Çalışmada $110 \mathrm{R}, 140$ $\mathrm{Ru}, 5 \mathrm{BB}$ ve $1103 \mathrm{~Pa}$ anacı üzerine aşılı Narince çeşidi kullanılmıştır. Sonuçlar incelendiğinde en yüksek kök uzunluğu değeri $1103 \mathrm{~Pa}$ ve $110 \mathrm{R}$ de $(8.5 \mathrm{~cm})$ de görülürken en düşük değer $140 \mathrm{Ru}(7.1 \mathrm{~cm})$ olmakla beraber sonuçlar yapılan çalışma ile paralellik göstermektedir.

Aşılı asma fidanı üretiminde anaç ve kalem birbirini fidan randımanı ve kalite özelliklerinin dışında olgunlaşma, besin elementi alımı, hastalık zararılılara karşı mukavemet v.b gibi pek çok yönü ile etkilemektedir. Corso ve ark. (2016)'nın yapmış oldukları çalışmada son zamanlarda yeni yeni tanınan M4 anacı ve ticari olarak yer edinmiş $1103 \mathrm{P}$ anacı üzerine Cabernet Sauvignon çeşidini aşılamışlardır. İncelenen fiziksel ve biyokimyasal parametreler CS tanelerinin M4 üzerine aşılı asmalarda olgunlaşma oranı 1103Panacına aşılılara göre daha hızlı olmuştur. 
Çakır ve ark. (2013), Sultani Çekirdeksiz üzüm çeşidinin farklı amerikan asma anaçları ile aşı tutma oranının belirlenmesi üzerine yaptıkları çalışmada; kaynaştırma odasından çıkarılan aşılı materyalde dip kök oluşumu, boğaz kök oluşumu, süren göz sayısı ve çepeçevre kallus oluşumu bakımından en yüksek değerleri SO4, 110R, 41B ve 5BB amerikan asma anaçlarından elde ettiklerini bildirmişlerdir.

Nematodlara karşı hassasiyetlerin karşılaştırılması için yapılan bir çalışmada 1103P, 101-14, 5BB, SO4 ve 3309 anaçları çeşit olarak ise Thompson Seedless, Pinot- Noir ve Chardonay çeşitleri kullanmıştır. Beklenildiği gibi anaçların dayanıklılı̆ı çeşitlere göre oldukça yüksek bulunmuştur. Çeşitler kendi aralarında değerlendirildiğinde Chardonay en hassas çeşit olurken sıralama Pinot-Noir ve Thompson Seedless şeklinde değişmektedir (Aballay ve Vilches, 2015).

Jogaıh ve arkadaşlarının (2015) yapmış oldukları başka bir çalışmada 101-14Mgt, 1103P, 110R, $140 \mathrm{Ru}$, Fercal, Gravesac ve SO4 anaçları üzerine Cabernet Sauvignon çeşidi aşılanmış; şeker, organik asit, fenolik bileşikler, potasyum içeriği ve $\mathrm{pH}$ parametreleri incelenmiştir. Incelenen parametreler bakımından değişik anaçlar üzerine aşılı Cabernet Sauvignon kombinasyonlarında önemli farklılıklar gözlemlenmiştir. En yüksek malik asit ve $\mathrm{pH}$ değerine 101-104Mgt ve Gravesac anaçları ile oluşturulan kombinasyonlarda rastlanırken, fenolik bileşik içeriğine ait en yüksek değerlere 110R anacı ile oluşturulan kombinasyonlarda rastlanılmıştır.

Anaç-kalem kombinasyonlarının anatomik yapısı ve fizyolojisi hakında az bilgi vardır. Santarosa ve ark., (2015) yaptıkları çalışmada anaç-kalem kombinasyonlarında meydana gelen vejetatif gelişmedeki farklılıkları vasküler sistem ile açıklamaya çalışmışlardır. Çalışmada 1103P, 101-14Mgt ve SO4 üzerine aşılı Cabernet Sauvignon ve Merlot üzüm çeşitleri kullanılmış ve vejetatif büyüme değişkenleri değerlendirilmiştir. Kalemin farklı bölümlerinden (apikal, medyan ve bazal) bitkideki vasküler sistem yolu ile görüntüleme yapılarak anaç ve kalem ilişkisinden kaynaklanan vejetatif gelişmedeki farklıık açıklanılmaya çalışılmıştır. Çalışmada Cabernet Sauvignon/1103P ve Merlot/SO4 kombinasyonlarındaki vejetatif gelişim her iki çeşidinde aşılandığı 101-14Mgt kombinasyonlarından oldukça fazla bulunmuştur. Ve bu farklılık asma ksilem dokularındaki vasküler yapı ile ilişkilendirilmiş̧ir.

Markoviç ve arkadaşlarının (2015) yapmış oldukları çalışmada 'Prekupac' isimli şaraplık üzüm çeşidi 5BB, $41 \mathrm{~B}$ ve SO4 anacı üzerine aşılanmıştır. Yaprak alanı bakımından Prekupac/41B kombinasyonu en yüksek değeri verirken, en küçük alan Prekupac/5BB kombinasyonu ile elde edilmiştir. En fazla sürgün uzunluğu Prekupac/5BB kombinasyonu ile elde edilirken sıralama Prekupac/41B, Prekupac/SO4 şeklinde değişmektedir. Yine kombinasyonlar arasında budama artığı bakımından en yüksek değer Prekupac/5BB kombinasyonundan elde edilmiştir.

Aşı odası randımanı ve kallus gelişim düzeyinin incelendiği başka bir çalışmada çeşit olarak Merlot, Cabernet Sauvignon üzüm çeşitleri ile anaç olarak ise 5 BB ve $110 R$ anaçları kullanılmış ve çalışma 2012-2013 yıllarında olmak üzere 2 yıl boyunca gerçekleştirilmiştir. 5 BB anacı üzerine aşılanan Cardinal, Merlot, Cabernet Sauvignon üzüm çeşitlerinin aşı odası randımanları 2012 yilında \% 99,50, \%99,75 ve \% 99,50, 2013 yilında sirasıly $\% 74,25, \% 70,50$ ve $\% 86,75$ olarak belirlenmiştir. Aynı üzüm çeşitlerinin $110 \mathrm{R}$ anacı üzerine aşılanmasıyla aşı odası randımanları 2012 yılında sırasıyla $\% 96,50, \% 98,75$ ve $\% 98,75,2013$ yilında sırasıyla $\% 97,75 \% 96,25$ ve $\% 86,25$ olarak saptanmıştır (Alço ve ark., 2013).

Yağcı ve Gökkaynak (2016), Sultani Çekirdeksiz üzüm çeşidinde fidan randıman ve kalitesi üzerine anaç ve gölgeleme oranının etkisini araştırmışlardır. Çalışmada anaç olarak $140 \mathrm{Ru}, 110 \mathrm{R}$, Ramsey, $1613 \mathrm{C}$ ve $5 \mathrm{BB}$ anaçları kullanılmıştır. Gölgeleme için ise \% 35 , $\% 55$ ve $\% 75$ gölgeleme oranları kullanılmıştır. Genel olarak kök kalite parametrelerinde elde edilen değerler köklenmesi zor olan anaçlarda (140 R, 110 R) düşük olurken köklenmesi kolay olan anaçlarda (5 BB ve 1613 C) yüksek bulunmuştur. Gölgeleme oranı bakımından fidan randıman ve kalite açısından en iyi performans \% 55 gölge altında yetiştirilenlerden elde edilmiştir.

\section{SONUÇ}

Çalışmaların büyük bir kısmı dikkate alındığında; Vitis vinifera türüne ait çeşitlerde köklenmenin en iyi olduğu, Amerikan asma anaçlarının ise iyi derecede köklenenler (5 BB, 1103 Paulsen, Rup. Du Lot), orta derecede köklenenler ( $8 \mathrm{~B}$, Ramsey, SO4 vb) ve köklenmesi zor olan anaçlar (41 B, 110 R, 140 Ruggeri) gibi kategorize edilebileceği ve bunun da bu çalışma ile birebir örtüştüğü söylenebilir. Ayrıca bütün anaçlarda aşısız fidanlarda randıman aşılı fidanlara göre daha yüksek olmuştur.

Sonuç olarak elde edilen veriler aşılamanın tek başına randımanı azaltıcı bir unsur olduğunu göstermektedir. Aşısız ve aşılı fidan üretiminde kullanılan anaçların randıman sıralamaları hep aynı kalmıştır (Rup. Du lot ve 8 B hariç). Yani 5 BB anacı \%82 
ile aşısız fidanda en iyi değeri gösterirken \%54 ile de aşılı fidanda en iyi değeri göstermiştir. 140 Ruggeri ise hem aşısız fidanda (\%60) hem de aşılı fidan da (\%20) en düşük değeri vermiştir. Zor köklenen anaçlarda aşılama işlemi ile elde edilen randıman düşüklüğü çok daha keskin olmuştur. Nitekim; 1103 Paulsen anacında aşısız fidan randımanı \%80, aşııı fidan randımanı $\% 52$

\section{KAYNAKLAR}

Aballay, E. ve Vilches, O. 2015. Resistance assessment of grapevinerootstocksused in Chile to the root-knot nematodes Meloidogyne ethiopica, M. hapla, and M.Javanica. Cien. Inv. Agr. 42(3):407-413. 2015.

Ağaoğlu, Y.S. ve Çelik, H. 1978. Bazı Amerikan Asma Anaçlarında Ethrel Uygulamaları ve Dikim Şekillerinin Köklenme Üzerine Etkileri. Ankara Üniversitesi Ziraat Fakültesi Yıllığı, Cilt:27, Fasikül L'den Ayrı Basım.

Akman, İ. ve Ilgın, C. 1987. Tüplü Fidan Üretiminde Başarıyı Etkileyen Faktörler, TÜBİTAK Türkiye 1.Fidancilı Sempozyumu Bildirileri S. 52

Akman, İ., Ilgın, C. ve Kacar, N. 1989. Çeliklerin Dikimden Önce Suda Bırakılma Sürelerinin ve Parafinli Parafinsiz Dikimin Fidan Randıman ve Kalitesine Etkisi. Manisa Bağcılık Araştırma Enstitüsü, Yay. No: 33/1: 19

Alço, T., Dardeniz, A., Sağlam, M., Özer, C., Açıkbaş, B. 2015. Aşılı Asma Fidanı Üretiminde Farklı Çeşit/Anaç Kombinasyonlarının Așı Odası Randımanı ile Kallus Gelişim Düzeyi Üzerine Etkileri. Selçuk Üniversitesi Selçuk Tarım ve Gıda Bilimleri Dergisi-A27 (Türkiye 8. Bağcılık ve Teknolojileri SempozyumuÖzel Sayıs1).

Archbold, D.D., Hamilton-Kemp, T.R., Barth , M.M. ve Langlois, B.E. 1997. Identifying Natural Volatile Compounds That Control Gray Mold (Botrytis cinerea) during Postharvest Storage of Strawberry, Blackberry, and Grape J. Agric. Food Chem., 1997, 45 (10), pp 4032-4037

Archer, E. ve Strauss, H.C. 1985. Effect of Plant Density on Root Distribution of Three-Yearoldgrafted 99 Richter Grapevines. S. Afr. J. Enol. Vitic. 6, 25-30.

Archer, E. ve Strauss, H.C. 1989. The Effect of Plant Spacing on The Water Status of Soil and Grapevines. S. Afr. J. Enol. Vitic. 10, 49-58.

Aslan, K.A., Özcan, S., Kösetürkmen, S., Yağcı, A., Sakar, E., Bekişli, M.İ. ve Kılıç, D. 2015. Gaziantep İlinde Asma Fidanı Üretiminde Farklı Çeşit-Anaç Kombinasyonlarının Karşılaştırılması. Selçuk Üniversitesi Selçuk Tarım ve Gıda Bilimleri Dergisi-A 27 (Türkiye 8. Bağcılık ve Teknolojileri Sempozyumu Özel Sayıs1).

Atlı, H.S. ve Arpacı, S. 1993. Farklı Amerikan Asma Anaçlarının Dımışkı, Dökülgen ve Hönüsü Üzüm Çeşitleri ile Affinite ve Adaptasyonları. Antepfıstı̆̆ı Araştırma Enstitüsü, Gaziantep.

Baydar, N.G. ve Ece, M. 2005. Isparta Koşullarında Aşılı Asma Fidanı Üretiminde Farklı Çeşit/Anaç Kombinasyonlarının Karşılaştırılması. Süleyman Demirel Üniversitesi Fen Bilimleri Enstitüsü Dergisi, 9 (3).

Biron, M. 1948. Avrupa Üzüm Çeşitlerinin Türkiye (Trakya) İklimine İntibakları (Acclimatation Des Cepages Eupeens En Turquei (Thrace) 1937 A 1947). Tekel Basımevi, İstanbul.

Çakır, A., Karaca, N., Sıdfar, M., Baral, Ç. ve Söylemezoğlu, G. 2013. Sultani Çekirdeksiz Üzüm Çeşidinin Farklı Amerikan olurken; 41 B anacında bu durum sırasıyla $\% 66$ ve $\% 32$ olmuştur.

$\mathrm{Bu}$ araştırmada elde edilen sonuçlar tek yıllık çalışmaya dayalı olup, aynı anaç ve aşı kombinasyonlarının yıl tekrarı yapıldıktan sonra gözlenen bulgulardaki değerlendirme kesinlik kazanacaktır.

Asma Anaçları ile Aşı Tutma Oranının Belirlenmesi Yyü Tar Bil Derg (Yyu J Agr Sc1) 2013, 23(3): 229-235.

Cangi, R., Doğan, A., Balta, M. ve Yarılgaç, T. 1999. Aşılı Asma Fidanı Üretiminde Farklı Parafin Uygulamalarının Aşı Kaynaşmasının Seyri ve Fidan Randımanı Üzerine Etkileri. Türkiye III. Ulusal Bahçe Bitkileri Kongresi, ss.983-988.

Carew, M.E., Goodisman, M.A. ve Hoffmann, A.A. 2004. Species status andpopulation genetic structure of grapevine eriophyoid mites. Entomologia Experimentalis et Applicata. 111:87-96.

Çelik, H. 1983. Sera Koşullarında Tüplü Asma Fidanı Üretimi, Türkiye II. Bağcllık ve Şarapçılı Sempozyumu, Manisa s3-8.

Çelik, H. ve Ağaoğlu, Y.S. 1979. Aşılı köklü asma fidanı üretiminde farklı çeşit/anaç kombinasyonlarının aşıda başarı üzerine etkileri. Ank. Üniv. Zir. Fak. Y1llığı 79(1):222- 232.

Çelik, H. ve Ağaoğlu, Y.S. 1981. Aşılı köklü asma fidanı üretiminde farklı "çeşit/anaç" kombinasyonlarının aşıda başarı ile fidan verim ve kalitesi üzerine etkileri. Ankara Üniv. Ziraat Fak. Yayınları:766, Bilimsel Araştırma ve İncelemeler: 452, $19 \mathrm{~s}$.

Çelik, H., Ağaoğlu, Y.S., Fidan, Y., Marasal, B. ve Söylemezoğlu, G. 1998. Genel Bağcllı, Sunfidan A.Ș. Mesleki Kitaplar Serisi:1,Fersa Matbaacılık, Kızılay-Ankara.

Çelik, S. 2011.Namık Kemal Üniversitesi Ziraat Fakültesi Bahçe Bitkileri Bölümü Bağcılık Kitabı.Cilt:1 Tekirdağ.

Corso, M., Vannozzi,A., Maza, E., Vitulo, N., Meggio, F., Pitacco, A., Telatin, A., D’Angelo, M., Feltrin, E.,Negri, A., Prinsi, B., Valle, G., Ramina,A., Bouzayen,M.,Bonghi,C. ve Lucchin, M. 2015. Comprehensive Transcript Profiling Of Two Grapevinerootstock Genotypes Contrasting In Drought Susceptibilitylinks The Phenylpropanoid Pathway To Enhanced Tolerancejournal Of Experimental Botanydoi:10.1093/Jxb/Erv274.

Dardeniz, A. ve Şahin, A.O. 2005. Aşılı asma fidanı üretiminde farklı çeşit ve anaç kombinasyonlarının vejetatif gelişme ve fidan randımanı üzerine etkileri. Tarım ve Köyişleri Bakanlığı, Atatürk Bahçe Kültürleri Merkez Araştırma Enstitüsü Müdürlüğü Dergisi, Bahçe. 43 (2): 1-9.

Epstein, E. 2004. Plant Biologists Need to Get Back to Their Roots. Nature, 430, 829- 829.

Ergenoğlu, F. ve Tangolar, S. 1990. Aşı1ı Çeliklerde Köklenme, Aşı Yerinde Kallus Oluşumu ve Sürgün Büyümesi ile İlgili Araştırmalar. Çukurova Üniversitesi Ziraat Fakültesi Dergisi, 5 (2); 141-156.

Gerhard, R., Cheng-Yung, C. ve Schneider, F. 1971. Probleme Der Reben-Veredlung. Heft 8: 9-27.

Harmon, F.N. ve Snyder, E. 1934. Grape Root Distribution Studie.s. Proc. Amer. Soc. Hort.Sci, 32, 370-373.

Hunter, J.J. ve Le Roux, D.J. 1992. The Effect Of Partial Defoliation On Development AndDistribution Of Roots Of Vitis Vinifera L. Cv. Cabernet Sauvignon Grafted Onto Rootstock 99 Richter. Am. J. Enol. Vitic,43, 71-78. 
Hunter, J.J. 1998. Plant Spacing Implications For Grafted Grapevine. I. Soil Characteristics, Root Growth, Dry Matter Partitioning, Dry Matter Composition And Soil Utilisation. Afr.J. Enol. Vitic, 19, 25-34.

İlhan, İ. ve Yılmaz, N. 1991. Aşılı Asma Fidanı Üretiminde Katlama Şekli Ve Aşı Yerlerinin Bağlanması İle Parafinlemenin Fidan Randıman Ve Kalitesi Üzerine Etkileri. Manisa Bağcılık Araştırma Enstitüsü, Yay. No: 47/4: 11.

İş̧i, B. ve Altındişli, A. 2006. Bazı Üzüm Çeşitlerinin 41B ve $110 \mathrm{R}$ Amerikan Asma Anaçlarille Aşı Tutma Yüzdesi Üzerine Araştırmalar. Ege Üniversitesi Ziraat Fakültesi Dergisi, 43 (2): $13-25$.

İşçi, B., Altındişli, A., Kacar, E., Yıldız, D., Soltekin, O., Önder, S., Ünal, A. ve Savaş, Y. 2015. Farklı Asma Anaçları İle Aşılı Red Globe Üzüm Çeşidinin Fidan Randımanı Üzerine Bir Çalışma. Selçuk Üniversitesi Selçuk Tarım Ve Gida Bilimleri Dergisi-A 27 (Türkiye 8. Bağcıllk Ve Teknolojileri Sempozyumu Özel Say1s1): (2015).

Jogaiah, S., Kitture, A.R., Sharma, A.K., Upadhyay , A.K . ve Somkuwar, R.G. 2015. Regulation Of Fruit ve Wine Quality Parameters Of 'Cabernet Sauvignon'Grapevines (Vitis Vinifera L.) By Rootstocks In Semiarid Regions Of India. Vitis 54, 65-72.

Johnson, S. N., Gregory, P.J., McNicol, J.W., Oodally, Y., Zhang, X. ve Murray, P.J. 2010. Effects of soil conditions and drought on egg hatching and larval survival of the clover root weevil (Sitona lepidus). Appl. Soil Ecol. 44: 75-79.

Markovic, N., Przic, Z. Ve Rankovic-Vasic, Z. 2015. Rootstocks influence on leaf surface and vegetative potential of 'Prokupac' grape cultivar Acta Horticulturae (1099) 421-425.

Morton, L.T. 1979. Translated And Adapted From P. Galet . A Partical Ampelography. Ithaca And London, 248 ss.

Persuric, D., Bubola, M. ve Sradeka, S. 2015. Influence of bud number per vine on Istrian Malvasia yield characteristics grafted on different rootstock. Proceedings . 50th Croatian and 10th International Symposium on Agriculture . Opatija . Croatia (500-504).
Richards, D., 1983. The Grape Root System. Hortic. Rev, 5, 127-168.

Sağlam, H., Yağcı, A. ve Sağlam, Ö.Ç. 2005. Bazı Amerikan Asma Anaçlarında IBA Kullanımının Fidan Kalite ve Randımanına Etkileri Üzerine Araştırmalar. Türkiye 6. Bağcılık Sempozyumu Bildirileri, Cilt: I, Sayfa No: 554-560, Tekirdağ

Samancı, H. ve Uslu, İ. 1992. Aşılı Köklü Asma Fidanı Üretiminde Randıman ve Kalitenin Çeşit/Anaç Kombinasyonlarına Göre Değişiminin Araştırılması. Tarım ve Köy İşleri Bakanlığı, Bağcılık Araştırma Projesi.

Santarosa, E., Souza, P.V., Mariath, J.E. ve Lourosa, G.V. 2015. Physiological interaction between rootstock-scion: effects on xylem vessels in Cabernet Sauvignon and Merlot grapevines American Journal of Enology and Viticulture 67 (1) 65-76.

Sivritepe, N. ve Türkben, C. 2001. Müşküle Üzüm Çeşidinde Farklı Anaçların Aşıda müşküle Üzüm Çeşidinde Farklı Anaçların Aşıda Başarı Ve Fidan Randımanı Üzerine etkileri. Ulud. Üniv. Zir. Fak. Derg,15:47-58.

Sucu, S. ve Yağcı, A. 2015. Aşılama Öncesi Amerikan Asma Anaçlarına Ön Bekletme Uygulamalarının Fidan Randımanı Üzerine Etkileri. Selçuk Tarım ve Gıda Bilimleri Dergisi - A27, (Türkiye 8. Bağcılık ve Teknolojileri Sempozyumu Özel Sayısı), s 450-456, Konya.

Tandonnet, J.-P., Cookson, S.J., Vivin, P. ve Ollat, N. 2010. Scion Genotype Controlsbiomass Allocation And Root Developmen In Grafted Grapevine. Aust. J. Grape Wineres, 16, 290-300.

Tunçel, R. ve Dardeniz, A. 2013. Aşıl Asma Çeliklerinin Fidanlıktaki Gelişimi ve Randımanları Üzerine Katlamanın Etkileri. Tarım Bilimleri Araştırma Dergisi, 6 (1): 118-122

Yağci, A. ve Aydin, S. 2015. Asma Fidanı Üretiminde Farklı Gölgeleme Oranlarının Fidan Randıman ve Kalitesine Etkileri. Selçuk Tarım ve Gıda Bilimleri Dergisi, 27146-153, (Yayın No: 1774641)

Yağci, A. ve Gökkaynak, A.G. 2016. Sultani Çekirdeksiz Üzüm Çeşidinin Fidan Randımanı ve Kalitesi Üzerine Anaç ve Gölgeleme Oranının Etkisi. Ege Üniversitesi, Ziraat Fakültesi Dergisi, 53(1), 109-116. (Yayın No: 2729475). 